This item was submitted to Loughborough's Research Repository by the author.

Items in Figshare are protected by copyright, with all rights reserved, unless otherwise indicated.

\title{
Mixing and compaction of fibre- and lime-modified cohesive soil
}

PLEASE CITE THE PUBLISHED VERSION

http://dx.doi.org/10.1680/grim.14.00025

\section{PUBLISHER}

(C) ICE Publishing

\section{VERSION}

VoR (Version of Record)

\section{PUBLISHER STATEMENT}

This work is made available according to the conditions of the Creative Commons Attribution-NonCommercialNoDerivatives 4.0 International (CC BY-NC-ND 4.0) licence. Full details of this licence are available at: https://creativecommons.org/licenses/by-nc-nd/4.0/

\section{LICENCE}

CC BY-NC-ND 4.0

\section{REPOSITORY RECORD}

Gelder, Craig, and Gary John Fowmes. 2019. "Mixing and Compaction of Fibre- and Lime-modified Cohesive Soil”. figshare. https://hdl.handle.net/2134/18538. 


\section{Mixing and compaction of fibre- and lime-modified cohesive soil}

1. Craig Gelder MEng

Engineer, Kier Group PLC, Sandy, Bedfordshire, UK
2 Gary J Fowmes EngD, BSc, MSc

Lecturer, School of Civil and Building Engineering, Loughborough University, UK
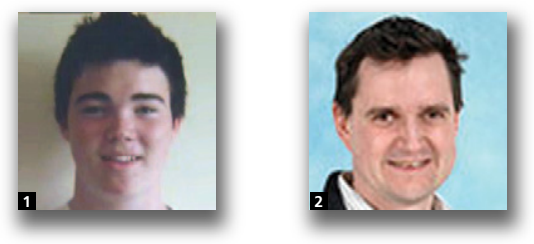

Fibre reinforcement is a versatile method of increasing the shear strength of soils for earthwork applications. However, research to date has encountered a number of problems when utilising cohesive host soils. The aim of this study was to develop a suitable site-applicable method of mixing fibre into cohesive host soils. Intermediate plasticity clay reinforced with monofilament polypropylene fibres was used in the laboratory investigations. In order to mix the fibres successfully, the initial moisture content of the host soil was increased prior to the introduction of fibres. By introducing quicklime, excess moisture was removed through the hydration process, and a portion of free water was effectively held within aggregations of flocculated clay particles, thereby having little influence on the dynamic boundaries. Fibrous inclusions within the clay clods resisted compactive effort, forming an interlocked structure. As a result, the optimum moisture content increased and the maximum dry density decreased. This trend was heavily dependent on the interfacial shear resistance along the fibre boundary, which consequently decreased as the water content increased or the compactive effort was increased. Results from strength tests confirmed that both peak and post-peak shear strength increased, creating a more ductile material capable of maintaining shear strength at high levels of strain.

\section{Introduction}

Many authors have highlighted an array of benefits associated with the addition of fibres to soils. In laboratory tests Consoli et al. (1998) and Cai et al. (2006) showed that the addition of fibres to soils alters the failure mechanism; the peak and postpeak (residual) strengths increased, and soils tended towards ductile failure as the fibres prevented the development of tension cracks. Previous studies on fibre-reinforced fine-grained soils have typically involved drying the soil to a powder prior to mixing. There is a need for a commercially viable mixing regimen that will achieve well-distributed fibre-lime mixes. Therefore, the aim of this study was to investigate the use of elevated moisture contents to facilitate mixing, and the use of lime to then reduce the moisture content to workable levels. The mixing behaviour and the complex interaction between the phases of fibre-soil-lime systems were studied.

\subsection{Fibre reinforcement}

Zornberg (2005) stated that the use of common design approaches, such as planar reinforcements anchored at the top of slopes, would not be feasible for steep or long embankments. Instead, he suggested the use of fibre reinforcement to stabilise veneers. By adopting this method of stabilisation, the strength isotropy of veneers is maintained, eliminating the planes of weakness, which lie parallel to traditional planar reinforcement (Zornberg, 2002). Li (2005) gave prominence to the use of discrete fibres in similar applications, emphasising their economic and technical viability. It may also be possible to use a geotextile-fibre composite solution (Gregory, 1998).

Failures of reinforcement often result in the need to remediate irregular sections. Traditional planar reinforcement can be used with difficulty in such circumstances but also requires further anchorage and excavation into the slope. Fibre-reinforced soil offers a significant advantage with regard to a flexible solution. Fibre reinforcement can also facilitate reinforcement of geotechnical barrier layers where continuous reinforcement may result in a preferential pathway for contaminant migrations (Fowmes et al., 2006).

In addition to the use of fibres to provide stability, a number of researchers have recommended adding fibres as a means to mitigate the formation of desiccation cracks (Abdi et al., 2008; Maher and Ho, 1994; Miller and Rifai, 2004; Zornberg, 2005). The formation of cracks within a containment liner, due to periodic wetting and drying, can pose significant risks with 
regard to the migration of leachates. Abdi et al. (2008) and Miller and Rifai (2004) demonstrated significant reductions in the development of cracks; the latter observing an $89 \%$ reduction in cracks with the inclusion of $0.8 \%$ fibre. Abdi et al. (2008) demonstrated the benefits of crack reduction for hydraulic conductivity, and noted an increase in strength as cracks were mitigated.

Figure 1 shows the morphology of the fibre-soil interface. Tang et al. (2007) identified four primary parameters that directly affect the interfacial shear resistance: friction, bonding force, matrix suction and interface morphologies. A further four indirect factors affect these parameters: water content, size effect, soil dry density and cement inclusions. To identify the physics at the micro-scale, Tang et al. (2010) and Li (2005) performed micro-mechanical tests using apparatus to assess single-fibre pull-out. While such tests may be criticised with regard to the non-uniform distribution of stress along the fibre due to a slight arching of the fibres (Michalowski and Cermák, 2003), they provide an important insight into the controlling interface mechanics.

\subsection{Mixing of fibres into cohesive soils}

Mixing of fibres into fine-grained cohesive soils can be problematic. A number of workers have added fibres to pre-moisture conditioned soils, using hand mixing to ensure sufficient mixing in terms of both distribution and orientation (AlWahab and Al-Qurna, 1995; Li, 2005; Freitag, 1986; Zaimoglu and Yetimoglu, 2011). In all cases the individual fibres clumped and matted to form fibrous balls that had to subsequently be prised apart and redispersed in the soil mass. To ensure distribution and prevent fibre balling, air-dried soil powders have been used, into which fibres are incrementally hand mixed prior to the addition of water (Amir-Faryar and Aggour, 2012; Tang et al., 2007). This method ensured the homogeneity of the mix and random orientation, but is not a viable methodology for use on-site.

Maher and Ho (1994) and Estabragh et al. (2012) produced mixtures by increasing the moisture content of soils above the liquid limit, with mixing by machine and by hand, respectively.
Maher and Ho (1994) prepared samples at twice the liquid limit. While homogeneity within each sample was ensured, the primary reason for mixing with slurry was to produce saturated samples and perform triaxial tests within shorter time periods. It would not be possible practically to create these high-moisture-content mixes on site. Importantly Maher and Ho (1994) identified the use of mechanical mixers as being the most site-viable method, although their use had the potential disadvantage that the fibres tended to drag or snare on the blades. However, oscillatory or helical mixing actions overcame such issues.

The first objective of the present study was to find an optimum mixing moisture content (OMMC), whereby cohesive soils could be conditioned to facilitate mixing but have a suitable moisture content for on-site mixing.

\subsection{Lime-fibre mixes}

Research to date has shown that the reaction of lime with clay results in three effects: moisture conditioning, cation exchange and pozzolanic reactions. The chemical composition and mineralogy of the soil are two key parameters that could potentially alter the lime-clay reaction. Beetham et al. (2014) have emphasised the need for in-depth knowledge of each particular case due to the variation in approach required. Of particular relevance to this study is the ability to modify the plastic properties and moisture content in order to facilitate a suitable mixing method.

When applying lime on-site, the development of clay clods during rotation or equivalent mechanical processes must be taken into account. The clods range in size up to $50 \mathrm{~mm}$ in diameter, and Beetham et al. (2014) have highlighted the implications of this physical trait on the sequential process of lime application, as the clods progressively alter the properties of the treated fill material. After distribution of the lime onto virgin soil, there is a tendency for there to be a high local concentration of lime on the surface of the clods, but for the required reactions to occur throughout the soil mass the calcium ions and hydroxyl ions must diffuse/migrate into the clods.

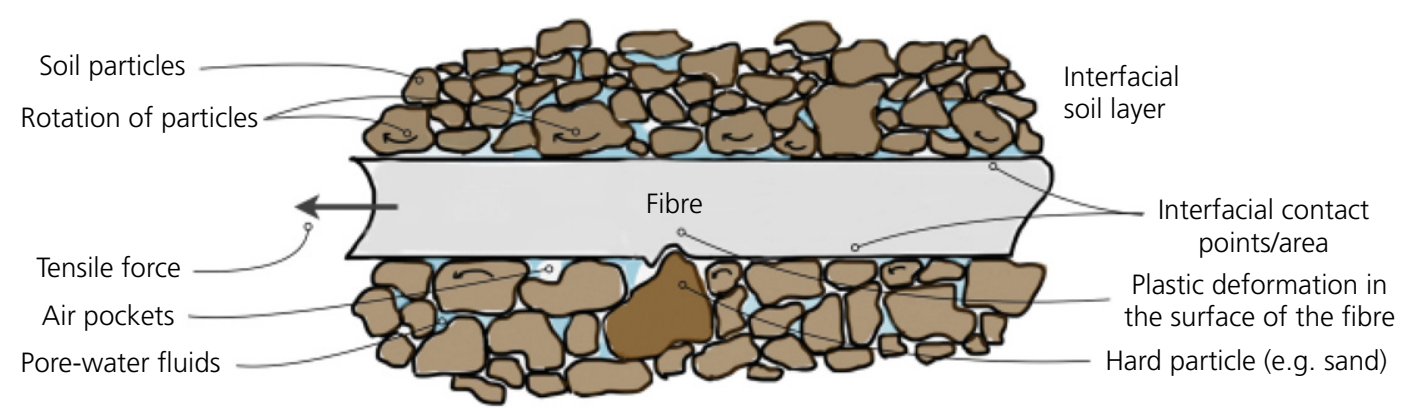

Figure 1. The fibre-soil interfacial zone. (Adapted from Tang

et al., 2007) 
The range of clod sizes is also important (Beetham et al., 2014). Clod size directly influences the rate of reaction of the lime in altering the strength and ductility of the mix: small and large clods will undergo rapid and slow rates of change, respectively. A uniform range of clod sizes is preferential, as any significant variations, along with quicklime, will exacerbate uneven reactions of the lime throughout the soil mass.

In this study, the use of lime to control sample moisture and the physico-chemical effects on the fibre-soil composite were investigated.

\section{Laboratory testing}

A series of compaction, mixing and unconsolidated undrained triaxial strength tests was carried out to assess the physical properties of the lime-fibre soil mixes. Quicklime was used in order to achieve increased drying of the samples through the exothermic reaction process. Prior to the application of lime, a reactivity test was carried out on the soils to BS EN 459-2:2010 (BSI, 2010). The temperature of the test exceeded $60^{\circ} \mathrm{C}$ in $1 \mathrm{~min} 30 \mathrm{~s}$, which is below the time of $25 \mathrm{~min}$ specified in clause 4.1.1 of BS EN 14227-11:2006 (BSI, 2006).

A search of the literature showed that testing has typically been done utilising fibre contents of $0 \cdot 05-1 \cdot 25 \%$, with a small number of tests having been conducted using higher contents of around 3-5\%, although with difficulty (Al-Wahab and Al-Qurna, 1995; Al-Wahab and Heckel, 1995; Amir-Faryar and Aggour, 2012; Anagnostopoulos et al., 2014; Cai et al., 2006; Chegenizadeh and Nikraz, 2011; Estabragh et al., 2012; Fowmes et al., 2006; Freitag, 1986; Zaimoglu and Yetimoglu, 2011). In the initial compaction tests done in this study, fibre contents of $0 \cdot 25 \%$ and $0.75 \%$ were used in order to obtain values at the lower and higher ends of the range. Subsequent tests were carried out using $0 \cdot 75 \%$ fibre content, on the assumption that if a mixing method could be developed to overcome the problems encountered at this fibre content it could be scaled down and applied to lower fibre contents. The properties of the fibres are presented in Table 1. The host soil was classified as a clay of intermediate plasticity in accordance with BS 1377-2:1990 (BSI, 1990).

\subsection{Mixing with fibres}

Trials of mixing were carried out using hand mixing and a z-blade mixer. The latter was found to produce suitable mixes within a reasonable time. Limitations regarding the use of the z-blade mixer and its representativeness to site use are acknowledged by the authors particularly in respect to the mix chamber being a confined space unlike the open boundaries of a site-based project. However, the z-blade mixer did demonstrate that even mixing could be achieved by mechanical means. Moreover, no effort was made to precisely distribute fibres in the mixer, yet the mix method effectively distributed the fibres without the need for precise distribution.
Material Polypropylene homopolymer

\begin{tabular}{ll}
\hline Length: $\mathrm{mm}$ & $18( \pm 10 \%)$ \\
Diameter: $\mu \mathrm{m}$ & 18 \\
Specific gravity: $\mathrm{g} / \mathrm{cm}^{3}$ & $0 \cdot 905$ \\
Elongation: \% & $50-180$ \\
Crimp level & Straight \\
Finish type & Hydrophilic type \\
Melting point & $160-165^{\circ} \mathrm{C}$ \\
Softening point & $153^{\circ} \mathrm{C}$ \\
UV stability & None
\end{tabular}

Table 1. Fibre properties

\subsubsection{Determining the OMMC}

Initial mixing trials were carried out at natural moisture content $(\sim 16 \%)$. From initial observations it was clear the fibres were poorly mixed into the soil mass. The addition of fibres transformed the sample from one initially consisting of small clods to one with larger clods as the fibres bound the soil. A proportion of these large clods were fibrous balls formed from a series of individual strands which knotted together during mixing (see Figure 2). These fibrous clumps proved difficult to pry apart; as a result any further increase in the mixing duration did not result in improved fibre distribution. The sample contained a significant quantity of fibre bunches which were not dispersed/broken down during the mixing process. These bunches were more easily identified due to the contrasting colour as seen in Figure 2. Breaking up the large clods of clay revealed additional smaller clusters of fibres. Only light finger pressure was required to dismantle some larger clods due to the limited fibre interconnection, highlighting the discontinuity of the fibres.

An increase in moisture content of the host soil to $20 \%$ markedly affected the quality of the mixed sample. In particular there was a reduction in the number of large fibre bunches and clumps. However, while the mix was improved, several issues still prevailed. Smaller clumps were still found throughout the mix. Furthermore, when a number of clods were dissected and inspected closely under an optical microscope, it was seen that the fibres had a tendency to entwine, forming rope-like features. Once again, such features reduced the area of interaction between the soil and the fibres. With regard to fibre bunches, there was a significant number of smaller bunches in localised areas. These concentrations of fibres and the consequent low fibre interconnections reduced the homogeneity and continuity of the mix. In addition, at the $20 \%$ moisture content there was a tendency for the mixture to drag on the mixer blades, and localised areas began to show signs of unidirectional orientation of the fibres in the mixing direction.

The initial moisture content of the host soil was then increased in $2 \%$ intervals. At a moisture content of $26 \%$ a homogeneous mix 
Ground Improvement

Volume 169 Issue GI2
Mixing and compaction of fibre- and

lime-modified cohesive soil

Gelder and Fowmes

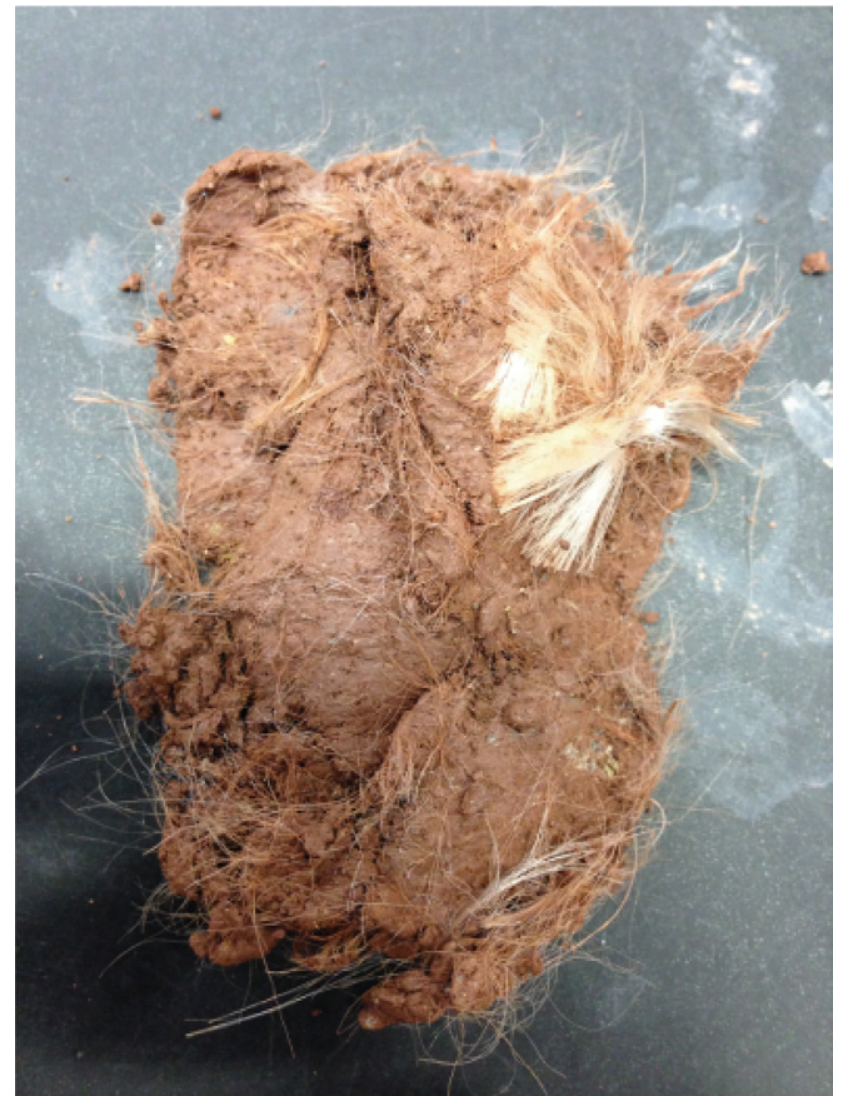

Figure 2. Fibre bunches found within the mix sample at $16 \% \omega_{c}$ (where $\omega_{\mathrm{c}}$ represents moisture/water content)

was achieved, with a uniform distribution of fibres throughout the mixture (Figure 3). Microscopic inspection of the sample confirmed this fibre distribution and the good soil-fibre interaction over an increased area. The mix showed no fibre clumps or bunches, except for a few that had become attached to the side of the mixing chamber out of the range of the mixing blades. Overall, $26 \%$ of the sample was found to be at the OMMC.

At moisture contents above $26 \%$ there was a substantial relapse in the quality of the mixture, particularly in terms of the dispersion of fibre bunches. Figure 4 shows bunches of fibres remaining after mixing the host soil with $34 \%$ moisture/ water content $\left(\omega_{\mathrm{c}}\right.$; liquid limit $2 \%$ ). Substantial fibre drag on the mixing blades reduced the homogeneity of the mix; the fibres progressively accumulated on the edges of the blades, increasing the local fibre concentration. One of the reasons why a homogeneous mix was not achieved may be the smearing of soil onto the mixing chamber base and sides such that a proportion of soil was outside the zone of action of the blades.

\subsubsection{Influence of lime drying}

The addition of quicklime reduced the moisture content of the soil-fibre samples mixed at the OMMC $(26 \%)$ to a value that depended on the lime content. Figure 5 shows the reduction in

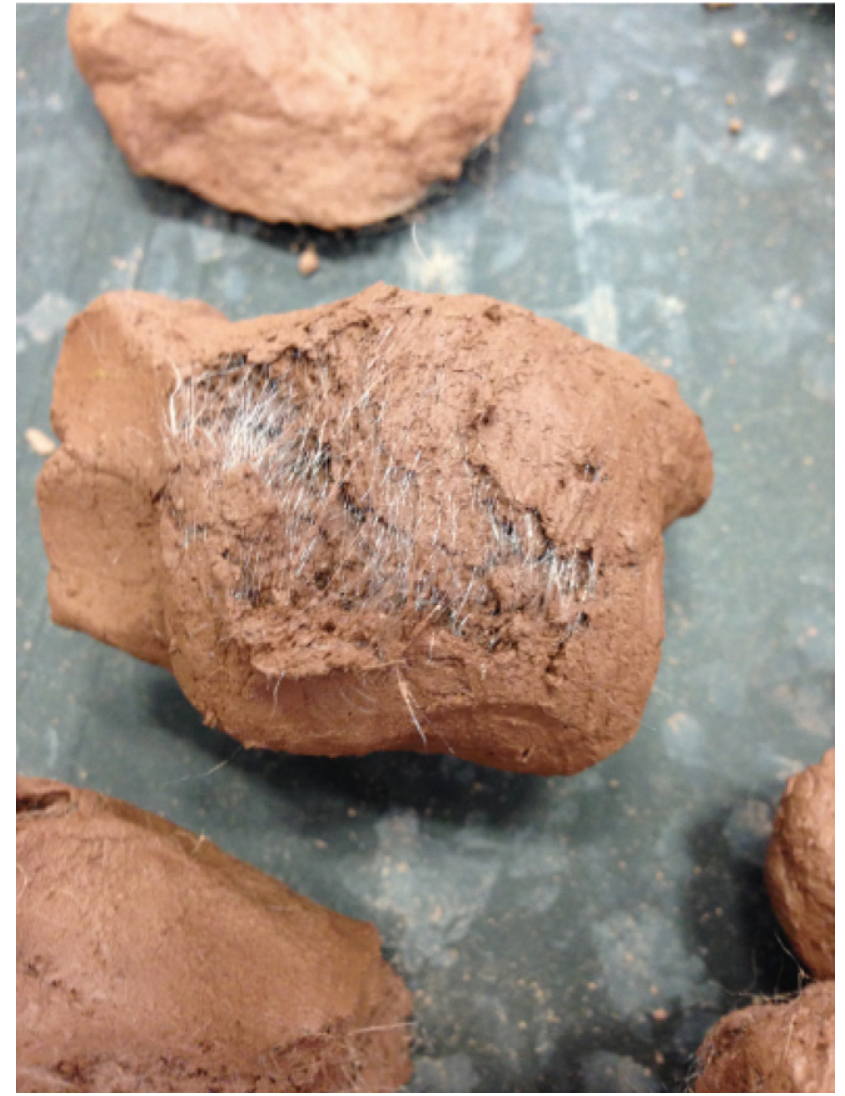

Figure 3. Homogeneous distribution of fibres within the mix sample at $26 \% \omega_{c}$

moisture content achieved in trials conducted using the z-blade mixer. The mixing chamber potentially hindered the evaporation of water due to poor airflow, so the glass window in the mixer lid was replaced with a metal mesh to improve airflow. There were also concerns that energy was lost into the mixer, which also restricted evaporation, and so the same quantity of soil was mixed by hand in trays in order to compare the moisture reduction achieved. Due to the difficulties of mixing fibrous soil by hand, these tests were performed without the addition of fibre. Two target moisture contents were set at $17 \%$ and $21 \%$ to represent bulk fill and barrier applications. A moisture level of $21 \%$ could be achieved with $6 \%$ lime content, but more than $9 \%$ lime would have been required to lower the moisture content to $17 \%$. The reductions in moisture content achieved in handmixed samples were only fractionally lower $(0 \cdot 4 \%)$ than those achieved using the mechanical mixer. In addition, the presence of fibres had a negligible effect on the reduction in moisture, suggesting that fibres do not inhibit the drying of samples.

\subsection{Compaction and clodding}

\subsubsection{Effect of fibre on compacted soil}

A series of standard Proctor compaction trials was carried out on samples containing $0 \cdot 25-0 \cdot 75 \%$ fibre. There was a decrease 
Mixing and compaction of fibre- and lime-modified cohesive soil

Gelder and Fowmes

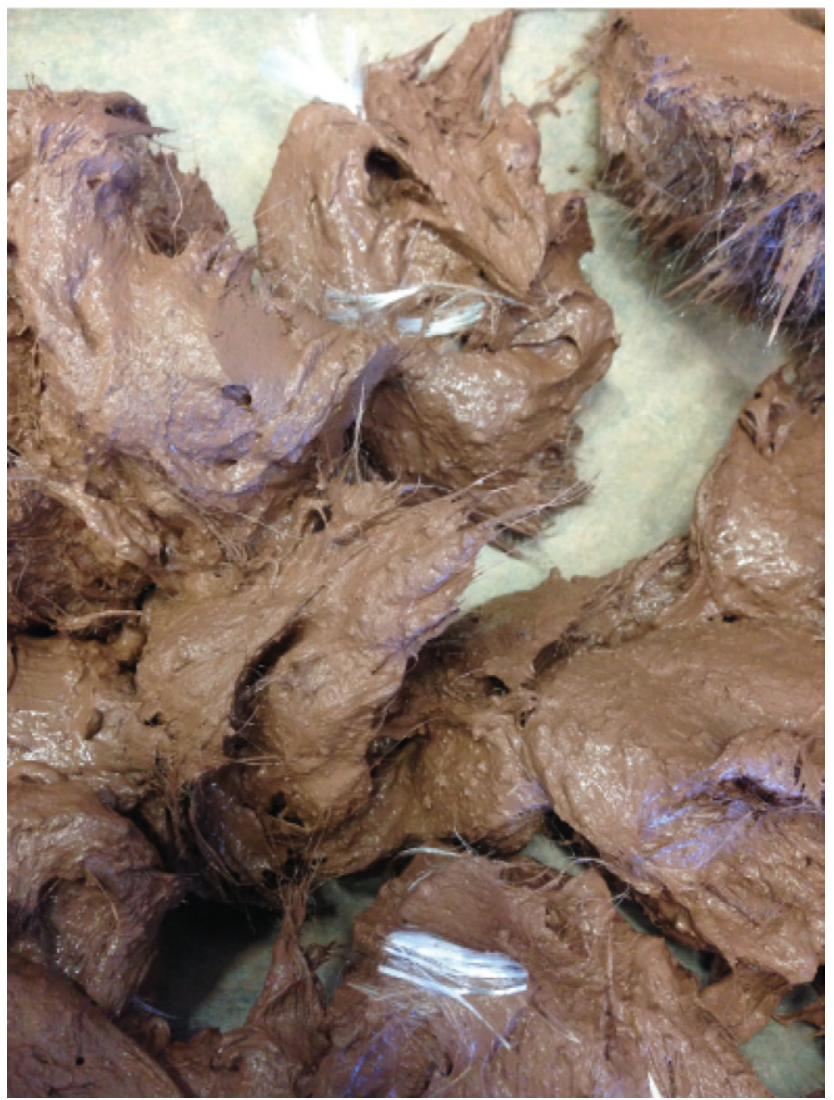

Figure 4. Poor mix quality with a number of fibre bunches remaining in the sample at $34 \% \omega_{c}$

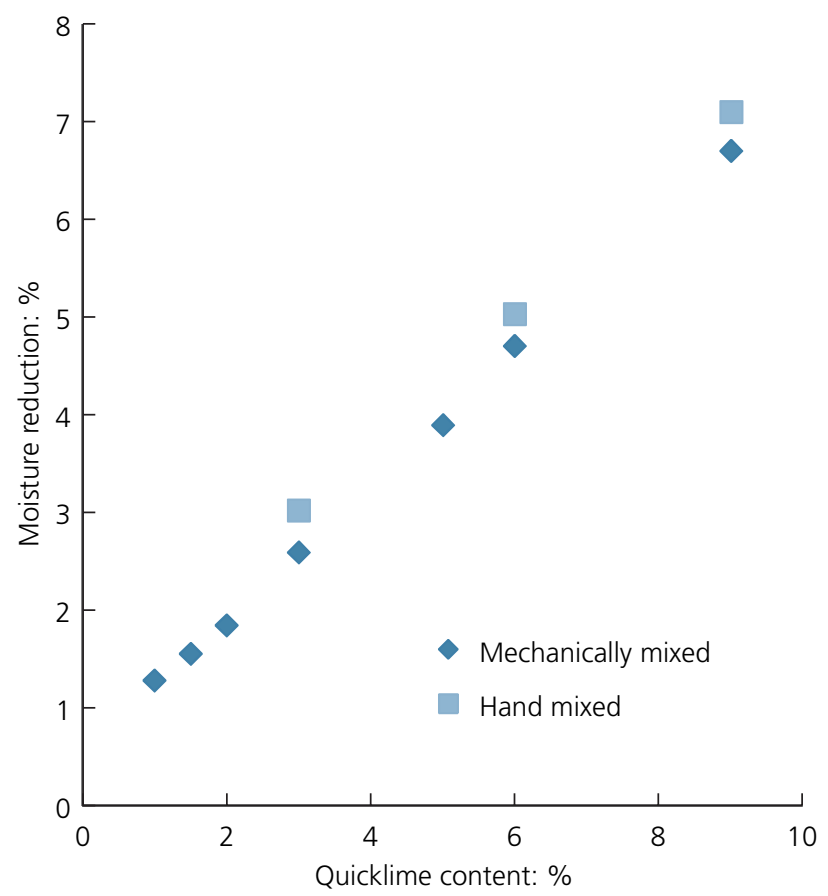

Figure 5. Variation in moisture loss with lime content for hand and mechanically mixed samples in the maximum dry density (MDD) and an increase in the optimum moisture content (OMC) with increasing fibre content. The addition of fibre to the clay soil did not change the compaction behaviour in terms of the shape of the Proctor curve but it did alter the compaction characteristics in terms of the MDD and OMC. The MDD was found to decrease by approximately $8 \%$ at $0 \cdot 75 \%$ fibre content, along with an associated $37 \%$ increase in the OMC (Figure 6). This contradicts the findings of a number of previous studies on the compaction of such soils. Fletcher and Humphries (1991) and Nataraj and McManis (1997) found the MDD and OMC to slightly increase and decrease, respectively. Further contradiction can be seen in the work by Amir-Faryar and Aggour (2012), who reported significant increases in the MDD. However, the results of the present study are in agreement with those reported by Chegenizadeh and Nikraz (2011) and the macro trend reported by Al-Wahab and Al-Qurna (1995), although neither reported changes of the same magnitude. It is logical that increases in fibre content will act to restrict compaction, as the compaction energy is taken by the fibres and the tension within the fibres resists particle densification.

Fibre reinforcement, in particular the fibre-reinforced clay clods, had a significant influence on the physical characteristics of the compacted soil. After compaction individual clods could often still be identified (Figure 7). Unlike unreinforced soil the clods do not appear to meld and form a uniform mass. Instead, the geometric structure is often more akin to a tightly packed interlocking granular matrix, while maintaining some ability to deform plastically, and, like a granular matrix with a uniform particle size, there are voids between adjacent particles.

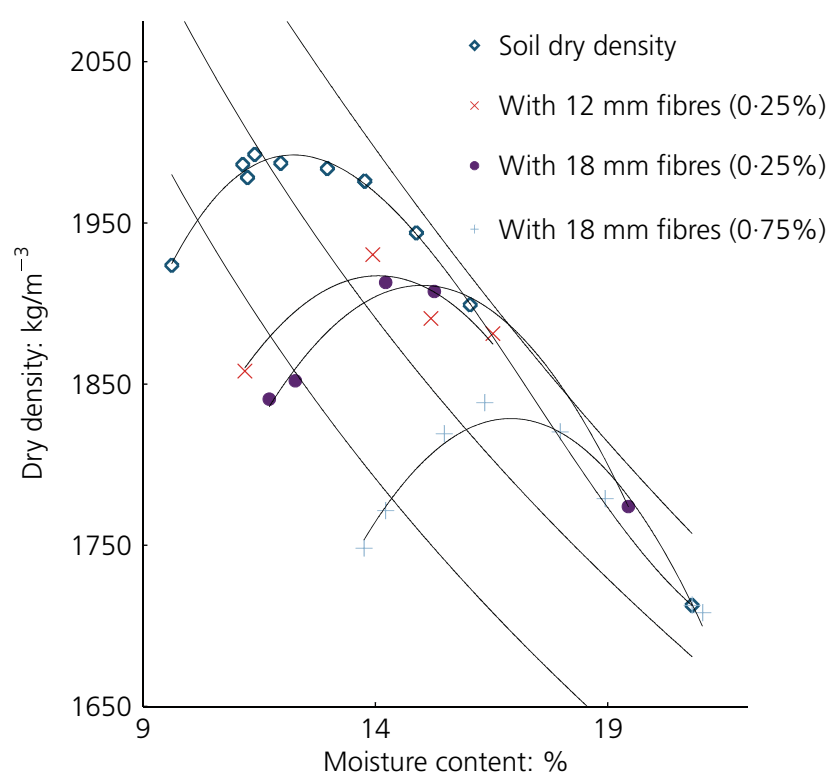

Figure 6. Dry density against moisture content for clay at different fibre contents and lengths 

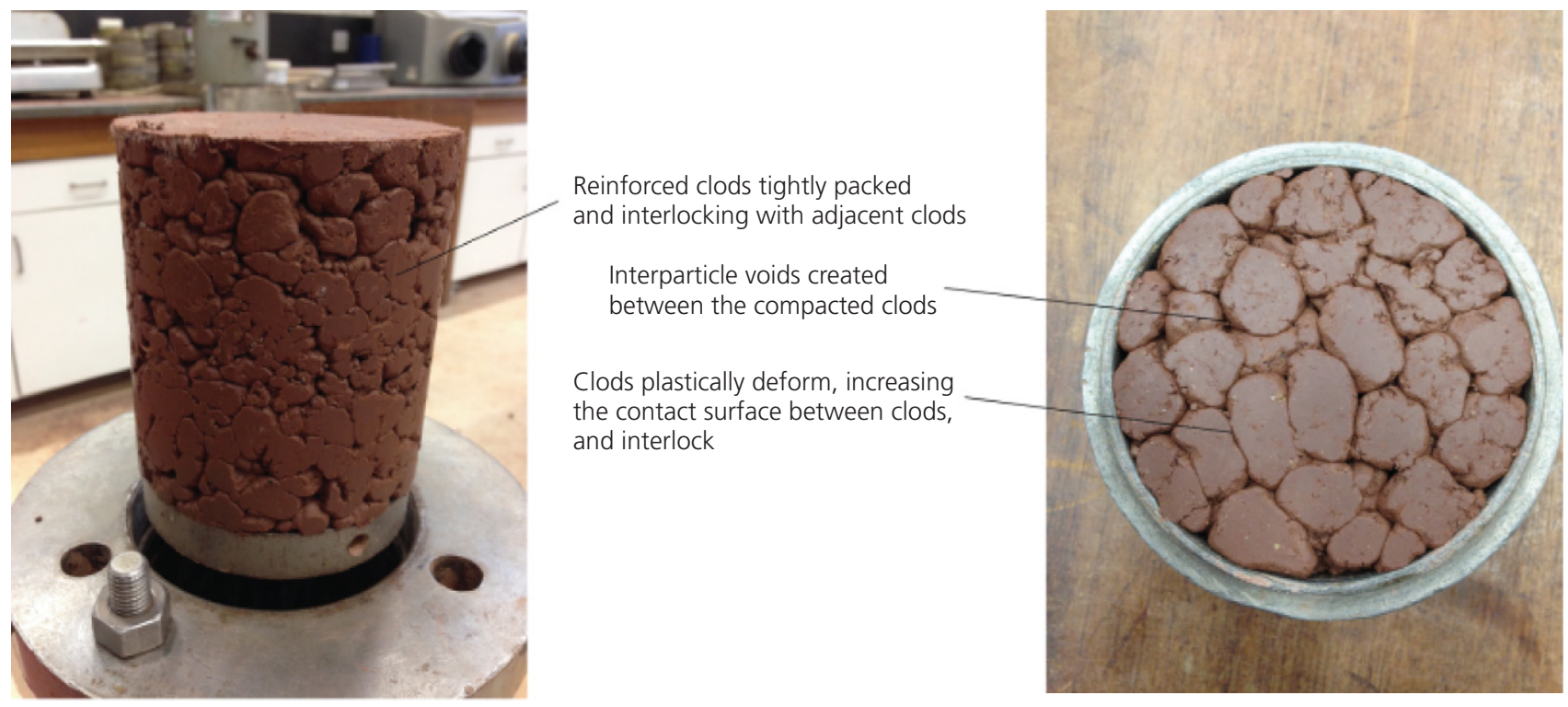

Figure 7. Fibre-reinforced Proctor sample with $18 \mathrm{~mm}$ fibres at $14 \cdot 18 \% \omega_{c}$

\subsubsection{Effect of lime on compacted fibre soil}

The addition of lime along with fibres reduces the MDD dramatically to $1680 \mathrm{~kg} / \mathrm{m}^{3}$ and increases the OMC to $21 \%$. The percentage change in the MDD and OMC is $-15.58 \%$ and $+75 \%$, respectively, compared with the values for soil with no additives. The changes with respect to fibre-only reinforced soil are $-8.5 \%$ and $+27 \%$. In addition, the inclusion of lime affects the compaction behaviour, there being a flattening of the Proctor curve for soil with lime added, as expected.

Clods appeared to dominate the structure of the compacted soil mass even at low percentages of lime and when the moisture content remained high (Figure 8). In the fibre-only reinforced soil, higher moisture contents produced increasingly more uniform and homogeneous Proctor samples. However, a reduction in the ductility of the soil, due to lime addition, still resulted in the interlocking clod structure. The large voids between clods were less evident at higher moisture contents, as the clods remained sufficiently ductile to compact tightly together. Higher lime contents (5\% and above) dramatically reduced the ductility of the soil. At these levels the clods deformed to a lesser extent, having a noticeable resistance under finger pressure. This resistance reduced the ability of the clods to deform during compaction. However, the aggregation of a proportion of the clay in these samples produced sufficient quantities of fine particles to fill the majority of the large spaces between clods. Deconstruction of the samples revealed the clod structure more clearly (see Figure 8(b)).

In fibre-only reinforced soils the melding of clods was typically due to cohesion in the case of dry clods, tending towards a combination of cohesion and fibrous connections as the moisture content and ductility of the soil increased. For soil containing lime, fibrous connections were seen across the range of samples. A number of factors controlled this trend. At low levels of lime (approximately 1-2\%), where clods remained highly ductile, microscopic inspection showed numerous fibres protruding from the surface of clods. Following compaction, signs of interconnection could clearly be identified when samples were deconstructed and the surface visually inspected. As the lime content increased, the ductility decreased and the surfaces of the clods became dry. However, unlike fibre-only reinforced soil, the fibres did not become locked into/onto the surface but were instead exposed due to the aggregation of the clay on the periphery of the clods.

\subsection{Strength and behaviour at failure}

The focus of the present study was on mixing and compaction, but it was important also to quantify the strength gains in order to better understand the behaviour of the composite materials. Strength was measured using an unconsolidated undrained (UU) triaxial test apparatus and samples were tested after mixing and compaction. Whereas standard triaxial samples are produced by extrusion of a Proctor sample using tubes and cutting rings, this procedure could not be used for reinforced samples because, when extruding the fibrous samples the fibres were caught along the cutting edge of the triaxial tube and the fibres were pulled from the soil, restricting the entrance of the tube and rendering the sample unusable. Samples were later prepared using individual precisionengineered moulds produced for $38 \mathrm{~mm}$ triaxial samples. Adequate samples could be made by compacting soil into these moulds. All attempts were made to ensure that the samples and methods used were comparable to standard samples and methods. 


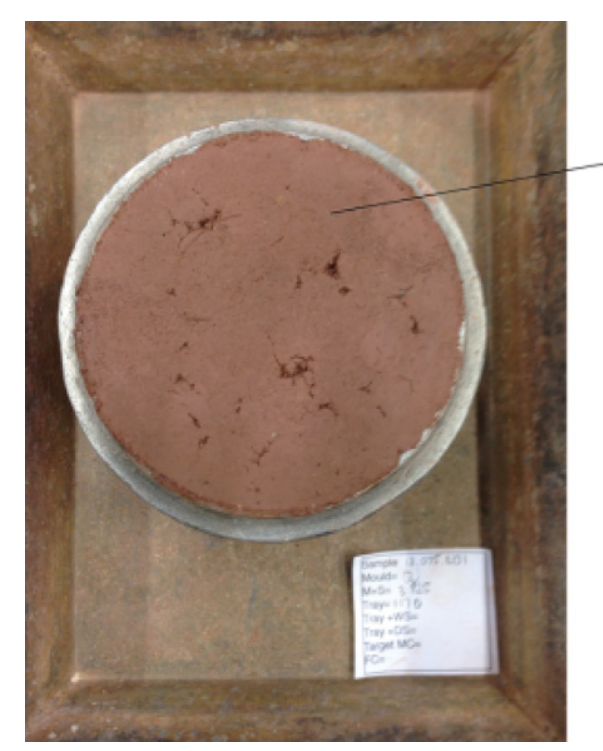

(a)

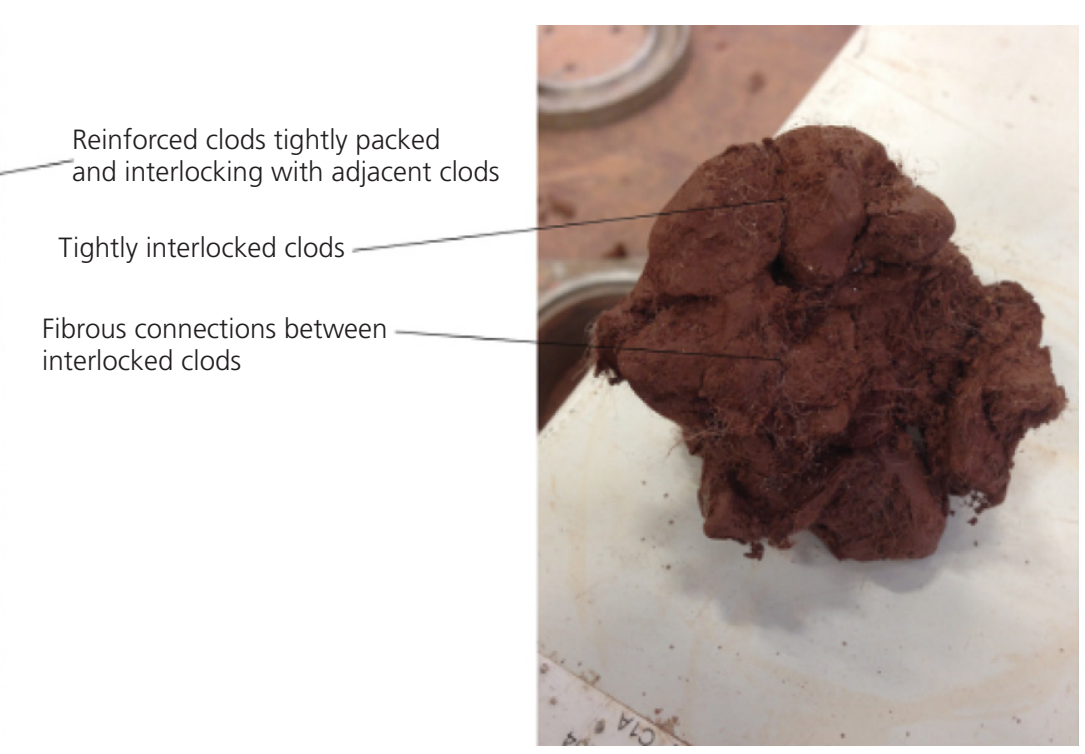

(b)

Figure 8. Fibre-reinforced Proctor samples: (a) sample with

$18 \mathrm{~mm}$ fibres and $1 \%$ lime at $24.72 \% \omega_{c i}$ (b) sample with $18 \mathrm{~mm}$

fibres and $1.5 \%$ lime at $24.45 \% \omega_{c}$, partially broken down to

show the interlocking structure

The samples were mixed at the target moisture content for the UU tests $(17 \%$ and $21 \%)$. Samples containing fibres were mixed at the OMMC (26\%) and allowed to air dry to $17 \%$ and $21 \%$ moisture content prior to compaction. Samples containing fibres and lime were mixed at the OMMC, and then the lime was added to reduce the moisture content to $21 \%$. Once mixed and at the desired moisture content, the material was placed into the moulds in layers of one-fifth the mould height and lightly tamped to remove air pockets. The mass of the material placed in the moulds was controlled to achieve target densities (Table 2) derived from the Proctor density curves for those samples. The top of the mould was pressed into place using a compression rig to compact the sample to the known volume. In order to achieve standard compaction, the force applied during the compression was calculated to be equivalent to that used for a standard Proctor test. Once the samples had been compressed they were extruded from the mould.

\begin{tabular}{lcccc}
\hline Sample & $\begin{array}{c}\text { Moisture } \\
\text { content: \% }\end{array}$ & $\begin{array}{c}\text { Fibre } \\
\text { content: \% }\end{array}$ & $\begin{array}{c}\text { Lime } \\
\text { content: \% }\end{array}$ & $\begin{array}{c}\text { UU sample } \\
\text { density: } \mathrm{kg} / \mathrm{m}^{3}\end{array}$ \\
\hline 1 & 17 & 0 & 0 & 1860 \\
2 & 21 & 0 & 0 & 1710 \\
3 & 17 & 0.75 & 0 & 1825 \\
4 & 21 & 0.75 & 0 & 1710 \\
5 & 21 & 0.75 & 6 & 1680
\end{tabular}

Table 2. UU triaxial sample density
It was attempted as far as possible to ensure that this alternative process of sample preparation satisfactorily represented the standard methods. However, there were difficulties in ensuring that air was removed from the sample and not trapped within pockets. While the authors acknowledge the sources of error, the method still provided a viable means of comparison between different samples, and reduced sample damage to the fibre-reinforced samples during extrusion core cutting.

Figures 9 and 10 show the increase in strength associated with the addition of $0.75 \%$ fibre at moisture contents of $17 \%$ and $21 \%$. The deviatoric stress at failure clearly decreased with increasing moisture content, and the influence of fibre

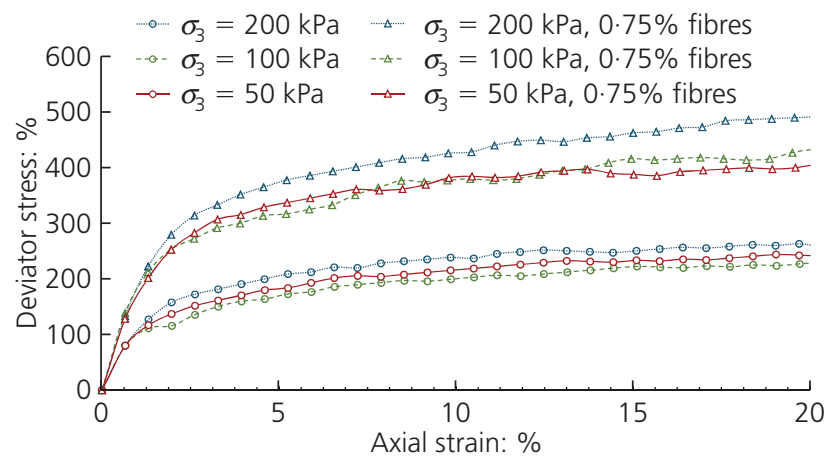

Figure 9. Stress-strain curves showing the influence of fibre inclusion at $17 \% \omega_{\mathrm{c}}$ 


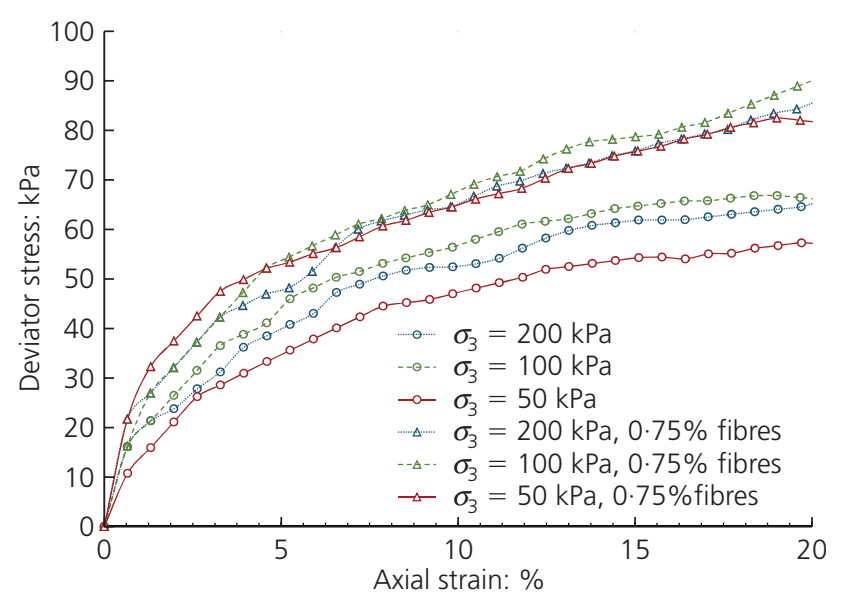

Figure 10. Stress-strain curves showing the influence of fibre inclusion at $21 \% \omega_{c}$

diminished at higher moisture contents due to the higher moisture content facilitating pull-out failure at the fibre-soil interfaces. Figure 11 shows the results for the addition of $6 \%$ lime at $21 \%$ moisture content. These results are presented to allow a direct comparison of samples at the same moisture content. However, the influence of the lime on the material composite is clearly dominant at this dosage, suggesting that lime-fibre mixes may be able to accept higher final moisture contents closer to the OMMC used for fibre mixing. The effects of lime and fibres are not mutually exclusive, and the addition of lime will alter not only the soil properties but also the soil-fibre interface behaviour. The hydrated lime product will develop on the surface of the fibres (Figure 12), increasing the surface roughness of the fibre, increasing

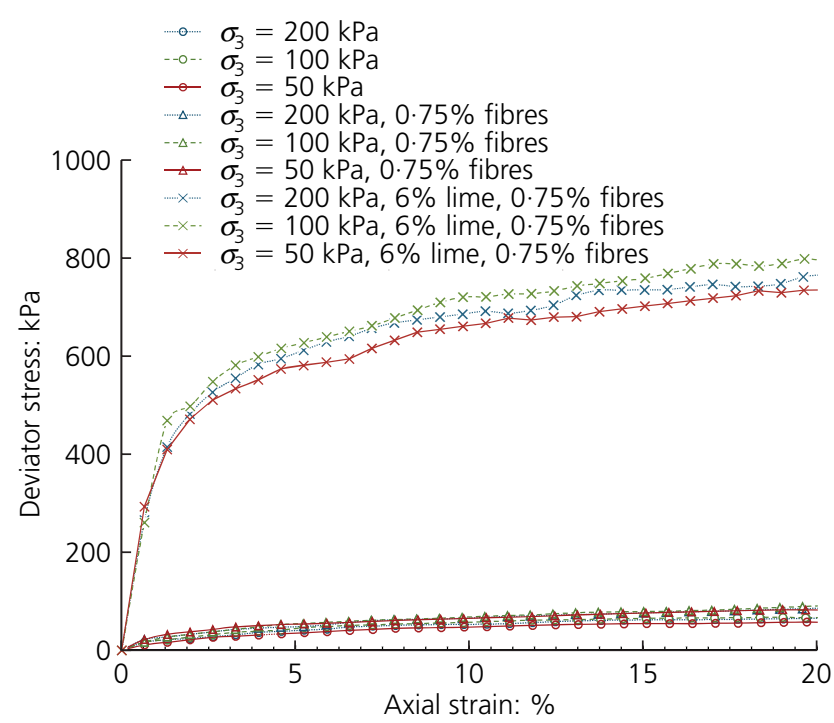

Figure 11. Stress-strain curves showing the influence of fibre inclusion at $21 \% \omega_{\mathrm{c}}$ with quicklime treatment pull-out resistance and thereby increasing the mobilised tension within the fibres. Moreover, a reduction of free water within the soil structure will also increase the fibre-soil frictional resistance.

The gain in strength due to the addition of lime was higher than anticipated given the time between mixing and testing. There would not have been sufficient time for pozzolanic reactions alone to account for the recorded increase in strength. The short-term strength increases can be explained by a reduction in the double diffuse layer thickness due to cation exchange, and an increase in the density of the electrical charge between the individual clay particles (Bell, 1996). These opposing forces cause the individual particles to flocculate (Beetham et al., 2014), resulting in aggregates of the order of silt in size. Initial pozzolanic reactions occur between the flocculated particle structure and the contacts between the clay particles (Figure 13).

\section{Discussion}

This study has highlighted the difficulties of compacting fibrereinforced soils and the implications resulting from the clodorientated compacted structure. Unlike the results of previous research, the addition of fibre was found to both significantly increase the OMC and significantly decrease the dry density. The portion of the literature that supported this trend found the changes to be of limited significance. While providing strength to the final composite, the fibres resisted the compactive effort, resulting in an interlocked structure of clods with a significant increase in the inter-clod porosity at lower levels of moisture. This suggests that the application of fibre-reinforced soils in containment applications may be somewhat compromised. However, the reinforced interlocked clods clearly affected the resistance of samples to deformation, increasing the strength of the composite. This ability to create an interlocked structure, interconnected by fibres, may prove advantageous in dynamic applications.

Analysis of the stress-strain curves confirmed that the presence of fibres improved the strength of the clay soil. The shear strength is affected by a number of interfacial mechanisms, not all of which could be assessed in this study, although previous research has demonstrated each parameter. However, the water content was assessed in the present study, and was found to reduce the effects of the fibres, confirming the results of previous studies.

It was necessary to vary the initial moisture content of the host soil in order to mitigate the problematic trends associated with the mixing in of fibres. The material-specific OMMC for the particular soil in this study was identified as $26 \%$. This represents a feasible increase in the in situ moisture content of material on-site, and may in some cases be already pertinent. At this level of moisture fibre could be evenly distributed throughout the clay soil using mechanical mixing methods. 


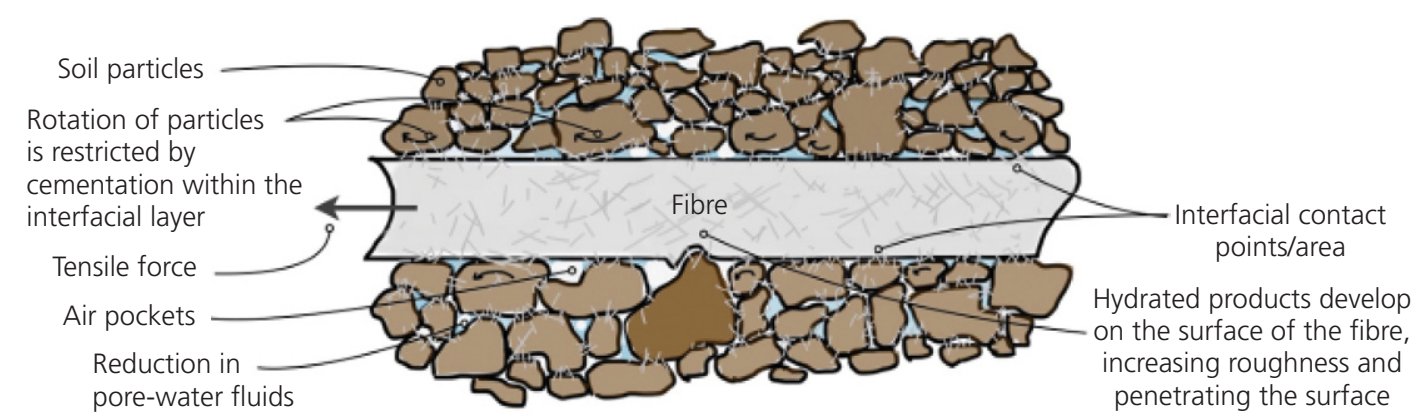

Figure 12. Effects of cement/lime addition on the mechanisms of interfacial shear

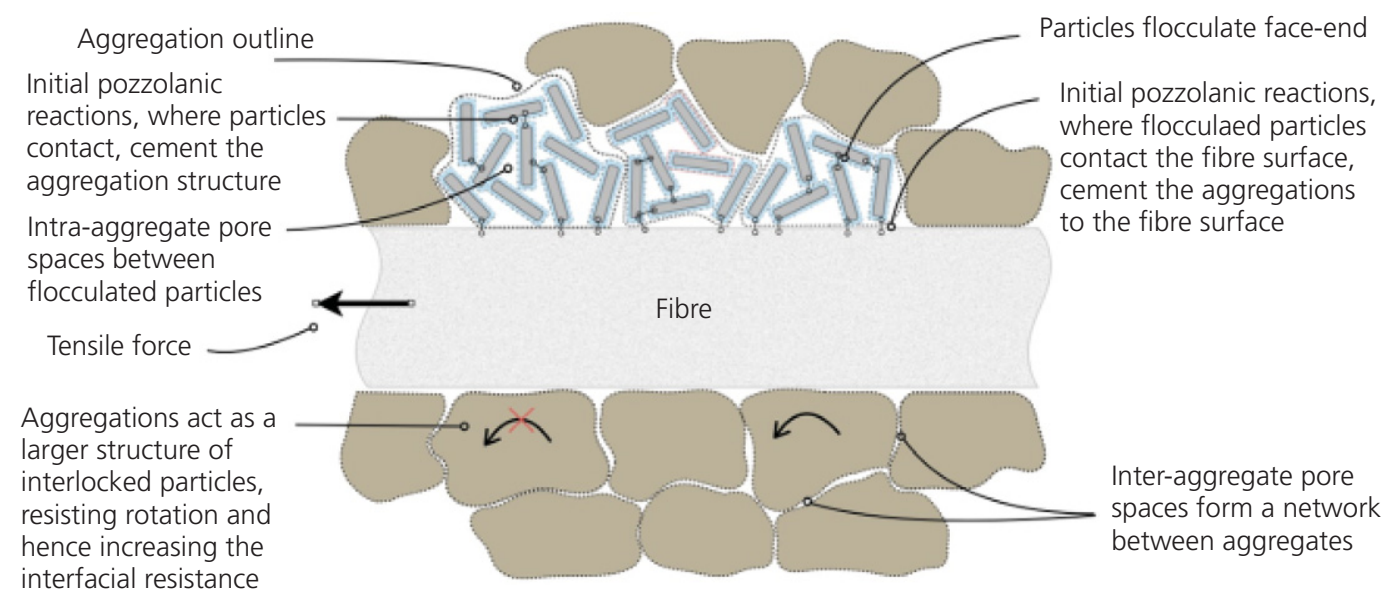

Figure 13. Flocculation and aggregation along the fibre interface

Compaction and mixing both induce shear strength anisotropy within the composite material. Compaction of the fibrous sample preferentially aligned the fibres parallel to the maximum tensile stress plane. In addition, the increase in the moisture content of the mix eliminated all but one of the mixing issues - the preferential orientation of the fibres. The preferential orientation tended to intensify as the moisture level increased, but this may be addressed with alternative mixing action. The reduction in strength isotropy may lead to the development of parallel failure planes or preferential flow of leachates.

The use of quicklime as a means of modifying the soil in order address the excess moisture in the mix proved advantageous in terms of time and practicality. However, in the present study excessive quantities of quicklime were used in order to achieve initial target moisture contents. These high contents would not be economically viable, and induced secondary stabilisation, whereby the lime provided the primary means of the increase in strength. However, the results did indicate the potential for the use of much lower quantities of lime. Quicklime removed moisture through the exothermic nature of the reaction of hydration but also isolated a proportion of moisture within the soil in the intra-aggregate pore spaces.

Successful mixing of each additive (water, fibre and quicklime) was dependent on the correct dosage. This could be effectively controlled within the confined chamber of a z-blade mixer. On-site mixing methods will need to be able to replicate this even distribution of additives in a practicable and economically feasible way. Plant such as pug mill mixers were identified as a potentially suitable means due to the confinement of mixing within a chamber. This equipment would be suitable for performing all stages of the mixing process.

Properties of both the host soil and the fibre can have significant effects on the behaviour of the fibre-soil composite. Comparison between the two host soils in this study showed a significant variation in the particle distribution for each material, which would affect a number of interfacial shear mechanisms along the soil-fibre interface. In addition, the plasticity of both the fibre-only and lime-treated fibrereinforced soil was found to affect the compaction characteristics and structure, again highlighting that the composite 
behaviour is dependent on material properties. Therefore, it is reasonable to conclude that material-specific testing should be undertaken to assess the potential behavioural variations expected.

\section{Recommended areas for further investigation}

A number of areas have been identified for further research. These include areas of research covered in this paper which require further investigation, and those areas that have not been addressed. Suggestions include the following.

The report provides a viable solution for mixing fibres into cohesive soils but further work will be required in a number of areas. The first of these is the use of lime to address the increased moisture content. The quicklime content trialled in the tests in this study was found to be too high and uneconomical. However, as discussed, there is a clear possibility that lower dosages of quicklime will still address the increased moisture content of the mix. As a significant quantity of the excess moisture was addressed by the changing properties of the clay and the exothermic drying, investigation into alternative forms of lime, such as hydrated (slaked) lime, should be undertaken. The addition of waste products such as pulverised fuel ash and fly ash may also increase the economic viability.

Larger scale mixing trials should be conducted using equipment available on site in order to further assess the possibility of adopting the method industrially.

Barrier systems require strict levels of permeability. Therefore, the effect of both the fibre-induced flow network and the interlocked clay clod structure should be investigated in relation to hydraulic conductivity.

\section{Conclusions}

Fibre reinforcement of fine-grained soil promises to provide an advantageous alternative to traditional engineering approaches for applications including slope stabilisation, landfill liners and pavement applications, to name a few. Fibrous additions have been shown to increase both peak and post-peak shear strength, and to improve the characteristics of soils, increasing their ductility. The random arrangement of discrete fibres produces an anisotropic composite with no potential for parallel planes of weakness or preferential flow paths. However, a major deterrent to the use of fibres within fine-grained soil, as opposed to granular materials, has been the difficulties encountered in mixing to achieve homogeneous samples. These difficulties have been identified in a large amount of the literature on the subject, and a number of laboratory-based solutions have been developed to overcome them. However, these methods have involved large increases in the moisture content or extreme drying, conditions that are suited to laboratory work but are not transferrable to the field. The overall aim of this study was to investigate and develop a suitable method of mixing fibres into fine-grained soils that could viably be applied to site applications.

The use of elevated moisture contents has been shown to produce effective fibre-soil mixing at a determined OMMC (for the soils described here, OMMC $=26 \%$ ). Mixing proved problematic both above and below the OMMC. The use of quicklime was shown to reduce the moisture content to the prewetting OMC levels. However, the doses of quicklime required to achieve this are not considered to be economically viable. Increases in the strength of fibre-lime composites were achieved in this study, and were found to be maximal at lime doses of $6 \%$. It is proposed that lower lime additions, with associated higher final moisture contents, would produce the required soil strength and compaction behaviour.

\section{Acknowledgements}

The authors would like to acknowledge the support of Drake Fibres, and the support of Lewis Darwin and Paul Beetham.

\section{REFERENCES}

Abdi MR, Parsapajouh A and Arjomand MA (2008) Effects of random fiber inclusion on consolidation, hydraulic conductivity, swelling, shrinkage limit and desiccation cracking of clays. International Journal of Civil Engineering 6(4): 284-292.

Al-Wahab RM and Al-Qurna H (1995) Fiber reinforced cohesive soils for application in compacted earth structures. Proceedings of Geosynthetics '95, Nashville, TN, USA, vol. 2, pp. 433-446.

Al-Wahab RM and Heckel GB (1995) Static and dynamic strength properties of a fiber-reinforced compacted cohesive soil. Proceedings of the Third International Conference on Recent Advances in Geotechnical Earthquake Engineering and Soil Dynamics (Prakash S (ed.)). University of Missouri, Rolla, MO, USA, vol. 3, pp. 1065-1072.

Amir-Faryar B and Aggour MS (2012) Determination of optimum fiber content in a fiber-reinforced clay. Journal of Testing and Evaluation 40(2): 334-337.

Anagnostopoulos CA, Tzetzis D and Berketis K (2014) Shear strength behaviour of polypropylene fibre reinforced cohesive soils. Geomechanics and Geoengineering 9(3): 241-251.

Beetham P, Dijkstra T and Dixon N (2014) Lime diffusion and implications for lime stabilization practice. Transportation Research Board 93rd Annual Meeting, Washington, DC, USA.

Bell F (1996) Lime stabilization of clay minerals and soils. Engineering Geology 42(4): 223-237.

BSI (British Standards Institution) (1990) BS 1377-2:1990: Methods of test for soils for civil engineering purposes. Classification tests. BSI, London, UK. 
BSI (2006) BS EN ISO 14227-11:2006: Hydraulically bound mixtures. Specifications. Soil treated by lime. BSI, London, UK.

BSI (2010) BS EN 459-2:2010: Building lime. Test methods. BSI, London, UK.

Cai Y, Shi B, Ng CW and Tang C (2006) Effect of polypropylene fibre and lime admixture on engineering properties of clayey soil. Engineering Geology 87(3): 230-240.

Chegenizadeh A and Nikraz H (2011) Compaction characteristics of reinforced clayey sand. Proceedings of the International Conference on Science and Engineering (ICSE). RG Education Society, Rohtak, India, pp. 352-355.

Consoli NC, Prietto PD and Ulbrich LA (1998) Influence of fiber and cement addition on behavior of sandy soil. Journal of Geotechnical and Geoenvironmental Engineering 124(12): 1211-1214.

Estabragh AR, Namdar P and Javadi AA (2012) Behavior of cement-stabilized clay reinforced with nylon fiber. Geosynthetics International 19(1): 85-92.

Fletcher CS and Humphries WK (1991) California bearing ratio improvement of remoulded soils by the addition of polypropylene reinforcement. Proceedings of the 70th Annual Meeting, Transportation Research Board, Washington, DC, USA, pp. 80-86.

Fowmes G, Dixon N and Jones D (2006) Use of randomly reinforced soils in barrier systems. Proceedings of the 5th International Congress on Environmental Geotechnics, Cardiff, UK, pp. 709-716.

Freitag DR (1986) Soil randomly reinforced with fibers. Journal of Geotechnical Engineering 112(8): 823-826.

Gregory G (1998) Reinforced slopes using geotextile-fiber composite. Proceedings of the 30th Annual Southeastern
Transportation Geotechnical Engineering Conference, Dallas, TX, USA.

Li C (2005) Mechanical response of fiber-reinforced soil. $\mathrm{PhD}$ thesis, The University of Texas at Austin, TX, USA (unpublished).

Maher M and Ho Y (1994) Mechanical properties of kaolinite/ fiber soil composite. Journal of Geotechnical Engineering 120(8): 1381-1393.

Michalowski RL and Cermák J (2003) Triaxial compression of sand reinforced with fibers. Journal of Geotechnical and Geoenvironmental Engineering 129(2): 125-136.

Miller CJ and Rifai S (2004) Fiber reinforcement for waste containment soil liners. Journal of Environmental Engineering 130(8): 891-895.

Nataraj M and McManis K (1997) Strength and deformation properties of soils reinforced with fibrillated fibers. Geosynthetics International 4(1): 65-79.

Tang C, Shi B, Gao W, Cai Y and Liu J (2007) Study on effect of sand content on strength of polyprolylene fibre reinforced clay soil. Chinese Journal of Rock Mechanics and Engineering 1: 2968-2973.

Tang C, Shi B and Zhao L (2010) Interfacial shear strength of fiber reinforced soil. Geotextiles and Geomembranes 28(1): 54-62.

Zaimoglu AS and Yetimoglu T (2011) Strength behavior of fine grained soil reinforced with randomly distributed polypropylene fibers. Geotechnical and Geological Engineering 30(1): 197-203.

Zornberg J (2002) Discrete framework for limit equilibrium analysis of fibre-reinforced soil. Géotechnique 52(8): 93-604.

Zornberg JG (2005) Geosynthetic reinforcement in landfill design: US perspectives. International Perspectives on Soil Reinforcement Applications 2005. American Society of Civil Engineers, Reston, VA, USA, pp. 1-12.

\section{WHAT DO YOU THINK?}

To discuss this paper, please email up to 500 words to the editor at journals@ice.org.uk. Your contribution will be forwarded to the author(s) for a reply and, if considered appropriate by the editorial panel, will be published as discussion in a future issue of the journal.

Proceedings journals rely entirely on contributions sent in by civil engineering professionals, academics and students. Papers should be 2000-5000 words long (briefing papers should be 1000-2000 words long), with adequate illustrations and references. You can submit your paper online via www.icevirtuallibrary.com/content/journals, where you will also find detailed author guidelines. 